\title{
Analysis on the Children Medical Autonomy
}

\author{
Xiaonong Zhang
}

\author{
Biological Sciences, UCL, London, WC1E 6BT, UK \\ Corresponding author. Email: gaoming@cas-harbour.org
}

\begin{abstract}
In modern medical treatment, children are always considered immature to make crucial decisions. It seems to be conventional for someone else to do it for the children. Most of the time, there are more advantages, but it also raises many problems. To examine those problems and their most reasonable solution, few cases and the theory principalism about children medical autonomy have been reviewed. The past research of people's preference in making medical decisions by Kavitha et al. 2020 has also been investigated. As a result, educational approach and the set up of appropriate legislative system will both be the basis to support the children's right to autonomy.
\end{abstract}

Keywords: Autonomy, Medical Ethics, Children, Principalism

\section{INTRODUCTION}

The notion of autonomy was first applied to the Greek city-state, where residents formed their own rules, where auto means "self" and nomos means "rule" or "law." A theorist then introduces this theory to explain many intuitions, conceptual and empirical issues, and normative claims that we should respect their own will and decision [1]. When related to medical autonomy, it often refers to patient self-determination, for example, deciding whether to continue the treatment. However, when it comes to children, the parents or guardians often take the responsibility of making such a decision. Which often bring ethical dilemmas in many situations, It is very important to distinguish what is best for the children and value the sense of personal autonomy whenever you have to choose between an ethical dilemma. Therefore, I will be discussing children's medical autonomy under different situations, and how we could deal with the balance between children autonomy and parental responsibilities in medical ethics.

\section{THE PROBLEMS EXISTED IN CHILDREN MEDICAL AUTONOMY}

The free will of people plays a significant role in theories of autonomy. There are three theories about free will: hard determination - we have no free will of our own, the environment shapes all the opinions. Soft determination - behaviors can be both determined and free. Liberation means that all of our actions are intentional actions that only come from our own will [2].
What is unique about children is that they are often considered immature and easily affected by the environment, which can not be responsible for making decisions. A life-saving surgery will need agreement from their guardians in almost all countries.

The point is that the child may disagree with what their guardians decided, the child may want to stop cure himself because of the pain during the treatment, or the parent refuses the treatment from the physician because of various reasons, like economic issues, religion. It raised many problems in medical ethics, over 200 children have died in the United States before 2004 as a result of their parents that relying on spiritual healing rather than the treatment given by the physician [3]. Under this situation, we should really make the decision that do no harm to the children.

In the case of Ms.L, where her partner Mr.X insisted on refusing the surgery because of long-term economic difficulties even when his partner and the baby fell into a coma, In the end, Ms.L and her child both died without any extra effort to save them. On January 24, 2008, Ms.L's parents filed a lawsuit against the hospital, The court judged the hospital had no responsibility for this case and only gave a plaintiff of 100,000 yuan $(14,500 \$)$ on humanitarian grounds, and the second instance upheld the original judgment [4]. In this case both the child and Ms.L lose their medical autonomy, died even when the treatments are still available. They are not under any legislative protections, the hospital respected Ms.X's opinion without asking for the patients' opinion. 
This case showed the lack of legislative protection in Children autonomy and presented a traditional Chinese family. That takes the family decision beyond individual autonomy, the parents are often reasonable to make decisions for the child, as they are the elder member of the family who have authority in the family. This phenomenon is mostly coming from the concept of Confucianism, an individual should working towards the greater good of the society, which forms the unique concept of traditional Chinese Families [5]. Although the concept of autonomy has now become more common in Chinese society, more actions and built up of new legislation are still needed to protect some children from this situation.

\section{TO WHAT EXTENT SHOULD THE CHILDREN HAVE THE RIGHT TO MAKE DECISIONS?}

Whenever the children are said to be incompetent for making the medical decision because of mental immaturity, this is referred to as a lack of capacity [6]. The value should be assessed bases on their ability to respond to the present situation and bear the corresponded consequences, be able to understand new environment or the reasons about hypothetical probabilities [7][8]. In medical ethics, the level of capacity is often separated into four groups: childhood, middle childhood, adolescence, and adulthood. During childhood, the caregiver will usually be the only decision-maker, and the children will not participate in decision-making. In the second stage however, the caregiver will be the final decision maker, it is considered ethical to inform all the information to the child and gain approval, but not necessary [9]. Where adolescents are the most complicated stages to medical autonomy, the physician will usually involve them in decision making. However, the person at this age usually has a very diverse capacity, and it is hard to tell how they think [10].

An investigation about decision-making on children medical autonomy in Scotland, interviews are carried with 176 physicians and nursing staff and 108 parents on their view for children medical autonomy, on most cases the parents believe that the parents should be primarily in charge of the decision making for their children [11]. The other investigation done by Kavitha et al. 2020 from 100 samples, investigated the preference on surgical decision making with pediatric plastic surgery patients and their caregivers. Where $40 \%$ of children and $67 \%$ of caregivers agree with shared decision-making between the patient, caregiver, and surgeon, $20 \%$ of children want complete autonomy, $60 \%$ of children prefer surgeondriven decisions [12].

This data changed significantly with their age, the children under 10 are more likely to refuse the suggestion given by caregiver and surgeon, where the caregiver prefers to give more autonomy when the child was male. Therefore, for those aged under 10 that cannot communicate and give their idea clearly, they should have the legislation that protects them from unwanted decisions. For example, in Islamic jurisprudent, the one who reaches Taklif (15 years old for boys and 9 years old for girls) will be treated as mature enough to make their own decision, also when if their parents are proven to be mentally abnormal or with bad faith that would cause harm to their children, the authority will be given to someone else that are eligible to make such decisions [13].Those aged 10 and up with clear thinking abilities should have their ideas considered and assistance in making their own decisions, not just because of the environmental impact.

Now the question is the legal age for children to have complete autonomy when making decisions related to medical treatment. In the United States, the physician must obtain agreements from the patients' parents when the patients are under 18. However there are also exceptions, for example, when the patients are under the emergency of a life-threatening situation, and the parents can not present on time, the consent can be diminished, whenever the patient situation back to normal, the consent for further treatment will still be needed, also for those parents that found with any domestic violence, a mental illness that might harm the children, their authority of making such decision will be deprived [14].

\section{WHY CHILDREN'S AUTONOMY IS SOMETIMES ABANDONED?}

Medical ethics are sometimes so difficult to decide not only because the decision are harmful to the children, we might just making decisions based on different aspects. One of the most famous theory about bioethics is principalism, which was mainly based on four moral principles: autonomy, nonmaleficence, beneficence, and justice. They can be used simultaneously, where one principle might outweigh another between different situations [15]. Then there is virtue ethics by Aristotle, where a virtuous act is what a virtuous person is doing. Consequentialism or utilitarianism by Jone Stuart Mill, where the consequences of your action are everything. Furthermore, Immanuel Kant's deontological ethics states that action itself will be intrinsically virtuous or wrong [2].

When it comes to decision-making, this could become extremely difficult. An example mentioned by Thompson in 2020, TJ is a seven-year-old boy with asthma, the situation has been stable from the treatment of using a corticosteroid inhaler and use of a bronchodilator inhaler [14]. Then TJ and his parent are asked to participate in the experiment on a newly developed drug for Asthma, there are minimal risks and also possibilities that their son will be making a full recovery from Asthma [14]. This is also the same for 
autonomy, we should always balance between the fourfactors and decide what are the most suitable ones that are best to the children, this standard also varies in different person.

Another factor that affects children autonomy I would like to mention is the cultural aspect. Just like the traditional Chinese family I have mentioned above, the idea of autonomy is seemed less important in the eastern history background, the cultural orientation is often described as "collectivistic" in contrast to "individualistic". Which surround by solid adherence to duties and role obligations, with support of group roles and obedience to authority [16]. The children or parents that grow up under this environment, are less aware of personal autonomy. Where the children in Western countries are offers educated with more sense of autonomous therefore is more familiar with making decisions on their own [16].

Then there will be the mental maturity of the children, they should be mature enough to make the choices that they would not regret.

\section{POSIBLE SOLUIONS}

The solution here is to enhance the education related to personal autonomy and the theory for principalism. So that the children will be more confident when faced with such a problem and make the right choice, as a basic psychological need in self-governance. They will be more likely to understand the problem they are facing and aware of the loss of personal autonomy, more mentally developed to make the right choices, and can intentionally report the difficulties to the appropriate organization for further actions [17]. This is also the same for those working in the medical constitution and the caregiver, they are the ones that are responsible for making decisions if the children are not competent to do so, therefore they should be fully trained or at least been educated about personal autonomy. The doctors, nurses, or other health care practitioners should be familiarized with the consent processes and be aware of the patient's right to know all the information even when the patient is under 18. From the legislation respective in British, all the healthcare partitioner will need to follow the Reference Guide to Consent for Examination or Treatment, the principles of the Mental Capacity Act (England and Wales) 2005, and the guidance from the Dignity in Care Campaign [18].

By starting from education or training for the children and the healthcare practitioner, we also need to set up a proper legislative system that the children could rely on. It is to create a basic standard to judge when the children's autonomy is offended and put in respective punishment if possible. It could also solve the source that directly affects the action of the caregiver, such as heresy or certain mental illness, which eliminates any problems that arise from an abnormality of the caregiver. The caregiver could lose Child custody if they are under severe mental illness [19].

What is interesting here is there are often no right choices that we can make according to the circumstances, what we need to do could be based on personal values and "quality of life" issues [8]. Here we could set a new position that placates the anxiety of the patients or the caregiver, give them time to make the right choices, and make sure the children's autonomy has been considered under decision-making processes. It is also ideal if the maturity of the children could be assessed when they are given the authority for making decisions.

There are also limitations of this research or solution that I am given is purely based on past experimental investigation or theories, a lot of other factors have not been included in this text. The idea is always not the same when it has been put into practice. We will need further actions to deal with many other problems like identifying particular parental mental illness, or setting up a clearer procedure to see if the child is competent in making such a decision. We will have to strengthen the ability to adjust to changing circumstances.

\section{CONCLUTIONS}

Children's autonomy is still a crucial issue during medical treatment, but now we should know that legal support is the basis for the children to protect their rights when the caregiver is not competent to make decisions. Secondly, we need to balance between the factors in principalism to decide what is best for the child when the children's autonomy conflicts with other factors. The aspects of education and legislation set up should be used in order to avoid many ethical dilemma when a clear boundary and sense of personal autonomy is awarded by everyone. The full capacity of participation in medical decisions should be given to the child whenever the situation allows. Hopefully, more actions will be taken against those children who lose their right to autonomy in the near future.

\section{REFERENCES}

[1] Dworkin. G. The theory and Practice of Autonomy. Cambridge University Press. 1988.

[2] Talbot. M. Bioethics: An Introduction. Cambridge University Press. 2012.

[3] Hickey. K, Lyckholm. L. Child welfare versus parental autonomy: Medical ethics, the law, and faith-bases healing. Theoretical Medicine Bioethics. 2004(25): 265-276.

[4] Zhang. H, Zhang. H, Zhang. Z, Wang. Y. Patient privacy and autonomy: a comparative analysis of 
cases of ethical dilemmas in China and the United states. BMC Medical Ethics. 2021(8).

[5] Tsai. D.F. Eye on religion: Confucianism, autonomy and patient care. Southern medical Journal. 2006(99).

[6] Parsapoor. A, Bagheri. A. Larijani, B. Patient rights in Iran. Med Ethics Hist. 2009(27): 39-47.

[7] Parsapoor. A, Parsapoor. MB, Larijani. B. 2005. Informed consent, contents, conditions and practical methods. Iran J Diab Lipid Disord. 2005(5): 1-15.

[8] McCabe. M.A. Involving children and adolescents in medical decision making: Developmental and Clinical Considerations. Journal of Pediatric Psychology. 1996. 21. 505-516.

[9] Canadian Paediatric Society. 2004. Treatment decisions regarding infants, children and adolescents. PaediatrChild Health. 2004(9): 99-114.

[10] Informed consent, parental permission, and assent in pediatric practice. Pediatrics. 1995(95): 314-7.

[11] Haffie. H.E, Laing. I.A, Parker. M, McMillan. J. Deceasing for imperiled newborns: medical authority or parental autonomy? Journal of Medical Ethics. 2001(27).

[12] Kavitha. R, Alexandra. O, Madeleine. H, Niki. M, Anne. P, Katelyn. M, Christian. V, Steven. K, Steven. B, Jennifer. W. Decision making in pediatric plastic surgery: autonomy and shared approaches. Journal of Cranionfacial Surgery. 2020(31): 2139-2143.

[13] Parsapoor. A, Parsapoor. M, Rezaei. N, Asghari. F. Autonomy of children and and adolescents in consent to treatment: Ethical, jurisprudential and legal considerations. Iranian Journal of Pediatrics. 2014(24): 241-248.

[14] Thompson. H. Children's Autonomy and Medical Decision Making. Student research. 2020: 164.

[15] Stearns. N, Krimsky. S, Boumil. M. Revisiting the essentials of medical bioethics. (Draft 5.31.05)

[16] Jacobs. J.E, Klaczynski. P.A. The Development of Judgment and Decision Making in Children and Adolescents. Psychology Press. 2006.

[17] Chirkov. V.I. A cross-cultural analysis of autonomy in education: A self-determination theory perspective. Theory and Research in Education. 2009. 7. 253-262.

[18] Redley. M, Keeley. H, Clare. I. Respecting patient autonomy: Understanding the impact on NHS hospital In-Patients of legislation and guidance to patient Capacity and consent. Journal of Health Services Research \& Policy. 2011. 16. 13-20.
[19] Deutsch. R.M, Clyman. J. Impact of mental illness on parenting capacity in a child custody matter. Family Court Review. 54. 29-38. 